\title{
NOTAS SOBRE A ASSIMILAÇÃO DA FILOSOFIA DA PRÁXIS PELO NEO-IDEALISMO E PRAGMATISMO: CROCE, DEWEY, GRAMSCI
}

\author{
Rosemary Dore*
}

\begin{abstract}
RESUMO
O presente texto tem como propósito estudar a indicação de Gramsci segundo a qual algumas posições do neoidealismo e do pragmatismo seriam inconcebíveis sem a assimilação da filosofia da práxis (marxismo). Tendo como referência análises do autor sobre a presença da filosofia da práxis no pensamento de Croce, realiza-se um primeiro movimento de aproximação teórica para investigar a existência de nexos entre algumas posições filosóficas de Croce e de Dewey. O ponto de partida é o exame da controvérsia entre Croce e Dewey, que teve lugar nos anos quarenta do século XX.
\end{abstract}

Palavras-chave: Filosofia da práxis. Gramsci. Croce. Dewey.

\begin{abstract}
The proposal of the present text is to study Gramsci's indication that some positions of neo-idealism and pragmatism would be inconceivable without the assimilation of the philosophy of praxis (Marxism). In the light of Gramsci's analysis of the presence of the philosophy of praxis in Croce's thought, the text starts an initial theoretical movement in order to investigate the existence of links between some philosophical positions of Croce and Dewey. The starting point takes in consideration the controversy between Croce and Dewey, which took place in the nineteen forty's.
\end{abstract}

Keywords: Philosophy of praxis. Gramsci. Croce. Dewey.

\footnotetext{
* Doutora em Educação: História e Filosofia da Educação pela Pontifícia Universidade Católica de São Paulo. Atualmente é professora de Filosofia da Educação do Curso de Pedagogia da Universidade Federal de Minas Gerais. E-mail: rosedore@fae.ufmg.br
} 


\section{Introdução}

Gramsci considera a filosofia da práxis, como chamava o marxismo, um momento da cultura moderna que modificou os velhos modos de pensar por ação e reação, uma verdadeira "reforma intelectual e moral". Por essa importância, ela forneceu conceitos a outras filosofias tradicionais, que permitiram a sua renovação. E isso se deu de modo explícito e implícito. A pesquisa da absorção explícita de conceitos da filosofia da práxis seria, em sua opinião, mais fácil de ser realizada. Essa é a linha da sua pesquisa sobre o pensamento especulativo de Croce. Já o estudo da absorção não explícita da filosofia da práxis por outras tendências do pensamento é mais difícil e delicado(GRAMSCI, 1977, p. 1233). Nesse sentido, Gramsci assinala como mais importantes o estudo sobre a filosofia "bergsoniana e o pragmatismo, para ver até que ponto algumas das suas posições seriam inconcebíveis sem o anel histórico da filosofia da práxis" (GRAMSCI, 1977, p. 1856).

A orientação de Gramsci para o estudo da assimilação da filosofia da práxis por outras tendências do pensamento não é a referência predominante na literatura que estuda a relação entre o pragmatismo e/ou o idealismo e a filosofia da práxis. Procura-se, ao contrário, identificar a presença do pragmatismo e do neoidealismo no pensamento de Gramsci. Essa é a abordagem de Chiara Meta (2004), Nadia Urbinati (1999) e Claudia Mancina (1999), por exemplo, que examinam as proximidades teóricas entre Gramsci e James ou entre Gramsci e Dewey, sugerindo a existência de convergências entre a filosofia da práxis de Gramsci e o pragmatismo. Enfim, a filosofia da práxis de Gramsci estaria em débito com relação ao pragmatismo.

Diferentemente dessa linha de análise, toma-se como referência, aqui, a indicação de Gramsci segundo a qual posições neoidealistas e pragmatistas assimilaram alguns conceitos da filosofia da práxis, levandose em conta seus estudos sobre o tema, especialmente sobre Croce. Com esse propósito, interroga-se a relação entre Croce e Dewey, o primeiro como expoente do neoidealismo na Itália e o segundo conhecido pela sua abordagem filosófica pragmatista.

Este trabalho faz parte de uma pesquisa mais ampla sobre o conceito de hegemonia, focalizando, sobretudo, a questão do "transformismo". 
Trata-se de um conceito formulado por Gramsci para explicar estratégias adotadas por grupos sociais dominantes no sentido de controlar, na teoria e na prática, a força de seus antagonistas no processo de transformação social e política. O fenômeno do "transformismo" consistiria, assim, nas formas através das quais os grupos sociais dominantes se apropriam de concepções, reivindicações ou exigências provenientes do movimento social e procuram acolhê-las - a concessão - mas as submetem à sua direção intelectual e moral, à sua hegemonia.

Num primeiro movimento de aproximação teórica para investigar a existência de nexos entre algumas posições de Croce e de Dewey, tomase como referência: 1) o debate entre os dois intelectuais, ocorrido no final dos anos quarenta do século passado; 2) algumas interpretações sobre o debate entre Croce e Dewey nos Estados Unidos e na Itália e 3) a análise de Gramsci sobre a assimilação da filosofia da práxis feita por Croce.

\section{Croce e Dewey: um debate "falido"}

Quando escreveu uma resenha sobre o livro de John Dewey intitulado Art as experience (1934), Croce (1940, p. 348-53) lançou, indiretamente, um apelo para estabelecer um diálogo com o famoso educador norteamericano. Era um convite para um intercâmbio intelectual em que Croce queria dar o tom teórico. Desse modo, encontrava no pensamento estético de Dewey pelo menos 18 pontos em que reconhecia a convergência de ideias entre ambos. No entanto, dizia que a afinidade de suas respectivas posições sobre a estética só era possível porque Dewey teria lido e se apropriado de ideias que já eram do conhecimento dos italianos há mais de trinta anos. Eram, enfim, suas próprias idéias ${ }^{1}$.

Como, então, o pragmatismo e o empirismo de Dewey poderiam constituir uma referência metodológica para a produção de conhecimentos que o próprio Croce teria afirmado há trinta anos?

\footnotetext{
1 Essa ideia, já presente no primeiro texto de Croce sobre Dewey ("Intorno all'estetica de Dewey", 1940) fica mais clara quando ele volta a debater com Dewey, dez anos mais tarde, escrevendo o texto "Intorno all'estetica e alla teoria del conoscere del Dewey" (CROCE, 1950). Sua tradução em inglês ganhou o título "Dewey's aesthetics and theory of knowledge" (1952). Nesse texto, Croce diz que o livro de Dewey Art as experience chega às mesmas conclusões sobre a Arte a que chegou a estética italiana trinta anos antes, quando então foi sustentado o seu ponto de vista em Estética (livro originalmente publicado em 1902).
} 
Para Croce, Dewey estava em débito com o seu pensamento. Um indicador dessa dívida era o fato de que as referências às suas fontes de pesquisa para produzir Art as experience eram muito vagas. Além disso, as verdades ali enunciadas sobre a estética entravam em contradição com a base de seu pensamento filosófico, que eram o empirismo e o pragmatismo. Como apoio ao seu argumento a respeito da existência de vínculos entre a reflexão de Dewey sobre estética e a filosofia idealista, Croce recorre à crítica de Stephen Pepper (1939) ao referido livro de Dewey. Pepper era um discípulo de Dewey e seu correligionário em pragmatismo, que também reclamara do livro do seu professor, dizendo que Art as experience não fora fiel aos princípios e métodos do pragmatismo, sendo dominantemente idealista.

Foi preciso que Croce esperasse oito anos para ver sua resenha publicada nos Estados Unidos. Ao mesmo tempo, conhece a resposta de Dewey (1948), que consiste num ardiloso e pequeno comentário, publicado na mesma revista. Seu preâmbulo apresenta uma ambiguidade concernente à posição de Croce na Itália fascista, que só pode ser intencional. Dewey diz apreciar a dedicação de Croce em examinar o seu livro, da mesma maneira que apreciou "sua heróica resistência à onda do fascismo que impressionou positivamente tantos pensadores italianos e educadores" (DEWEY, 1948, p. 207). Mas Dewey se recusa a aceitar o convite de Croce para um debate, afirmando não existir um terreno teórico comum(common ground) entre eles.

Opondo-se ao argumento de Croce sobre a existência de uma dívida em Art as experience com relação às fontes de pesquisa de autores italianos, Dewey declara não se sentir em débito com escritores que supostamente deixou de citar, especialmente em relação àqueles italianos, mencionados pelo seu crítico, "por uma espécie de xenofobia” (DEWEY, 1948, p. 208). Quanto aos dezoito pontos de possíveis convergências teóricas entre o seu pensamento e o de Croce, Dewey afirma que as teses abordadas em seu livro, embora não fossem propriamente "lugares comuns", eram bastante conhecidas no campo da estética. Por isso, considera uma surpresa a ideia de que estivessem subordinadas a algum sistema filosófico. Por fim, Dewey se refere a dois pontos destacados por Croce, para dizer que os extraiu justamente de fontes não filosóficas, como foi o caso do conceito de "expressão" e da premissa segundo a qual "o conhecimento histórico é indispensável para o julgamento da arte” (DEWEY, 1948, p. 209). 
Um ano depois de receber essa resposta, e a propósito do aniversário de noventa anos de Dewey, Croce lhe envia uma saudação pela data e escreve a respeito da recusa do educador estadunidense em debater com ele sobre arte e filosofia ${ }^{2}$.

Não tendo sido suficientes os dezoito pontos em que identificara anteriormente um "terreno teórico comum" entre ele e Dewey a respeito da Arte, Croce decide apresentar novas provas das semelhanças entre o seu pensamento e o de Dewey (CROCE, 1950). Desta vez, escolhe o campo da história e analisa argumentos de Dewey sustentados no livro Democracia e educação (originalmente publicado em 1916) ${ }^{3}$. Ali, Dewey afirma que "O verdadeiro ponto de partida da história é sempre uma certa situação presente, com seus problemas individualizados" (apud CROCE, 1950, p. 65). A teoria de que a história resulta de interesses do presente era a mesma que ele próprio, Croce, já anunciara em $1912^{4}$. Então, sustentara que

a história é apenas aquela que nasce de um interesse do presente que reanima e faz reviver o passado, e que sem esse espírito o passado permanece um amontoado de dados extrínsecos e desconexos, tal como são as anotações que são chamadas de crônicas e que, pelo fato de vir sempre animada por um interesse do presente, cada história viva e verdadeira é história não 'do passado', mas 'contemporânea' (CROCE, 1950, p. 65).

2 Quando, finalmente, Croce elaborou o segundo texto sobre a estética de Dewey, em 1949, tinham se passado nove anos desde a sua primeira crítica e Dewey fazia aniversário de noventa anos (A segunda crítica de Croce à estética de Dewey foi publicada em 1950). Nos Estados Unidos, sua resenha foi traduzida para o inglês por Katherine Gilbert e intitulada Dewey's aesthetics and theory of knowledge, sendo publicada no Journal of Aesthetics and Art Criticism, dia 11, em setembro de 1952, (p. 1-6), ano em que morreram os dois intelectuais: Croce aos 86 anos e Dewey aos 93 anos. O debate, que nunca houve, completava então doze anos.

3 Croce cita afirmações feitas por De Ruggiero (1931) em sua introdução a Ricostruzione filosófica, tradução para o italiano do livro de Dewey Reconstruction on philosophy (1920), e que são extraídas do livro de Dewey, intitulado Democracy and education. An introduction to the philosophy of education, 1930, p. 250-251.

4 Croce afirma que teria enunciado as mesmas teorias em seu livro Storia, cronache e false storie, originalmente publicado em 1912, em Atti dell"accademia pontaniana, e depois em Teoria e storia della storiografia, cuja primeira edição é de 1916. O texto foi traduzido para o inglês e publicado em 1921, com o título The theory and history of historiography. 
Com esses argumentos, Croce propõe comprovar que também a concepção de história de Dewey estaria fundamentada em sua própria reflexão sobre a história. Por isso, ela não poderia ser deduzida de premissas empíricas e pragmáticas, que supostamente orientavam o referencial teórico de Dewey. Ao contrário disso, a teoria da contemporaneidade da história resultava de uma demonstração especulativa. Como afirma Croce, seus próprios estudos lhe fizeram ver

o liame entre a história e a necessidade prática e moral, que a gera, e a passagem da verdadeira teoria da história à ação que a virtude prática e moral cria, e desta, de novo, ao momento cognoscitivo do qual irrompe a nova ação e desse modo até o infinito" (CROCE, 1950, p. 66).

Trata-se de um processo circular, assinala Croce, "no qual o fim se re-encontra sempre com o seu início; e o processo circular está na unidade do espírito, coincidente de fato com as distinções que dialeticamente o compõem" (CROCE, 1950, p. 66). Essa seria mais uma prova do fato de que os enunciados de Dewey não tinham como premissa o empirismo e o pragmatismo, mas resultavam de uma demonstração "especulativa", dada por ele, Croce.

Com base nesses argumentos, Croce critica a posição de Dewey sobre a verdade, pois o que Dewey denomina processo não seria processo, tendo em vista a sua incapacidade de superar o dualismo entre espírito e natureza. Foi o vínculo entre história e conhecimento que teria permitido a Croce concluir que a história nasce de interesses do presente.

\section{Croce e Dewey: qual o significado de um debate entre eles?}

A polêmica entre Croce e Dewey é muito conhecida tanto nos Estados Unidos quanto na Itália e sobre ela existe uma variedade de interpretações.

Nos Estados Unidos, uma das primeiras manifestações a respeito do debate entre os dois intelectuais partiu de Romanell (1949). Ele identificou concordâncias entre Dewey e Croce na concepção de que o objeto da 
Filosofia da Arte é a própria "experiência estética", embora distinguisse discordâncias entre os dois quanto à natureza específica da experiência estética. Mas, do ponto de vista geral da questão, afirma Romanell, era indiferente se Croce acreditava no caráter cognitivo dessa experiência e Dewey não.

Ainda tendo como cenário a polêmica entre Croce e Dewey, e no mesmo ano da morte de ambos, Simoni (1952) destacou dois aspectos desfavoráveis à aceitação das ideias de Croce nos Estados Unidos. De um lado, o fato de que ele apenas escrevia em italiano e poucos americanos liam essa língua. Por causa disso, muitos de seus trabalhos, recentes, ricos e refinados, eram desconhecidos do público americano. De outro lado, foi desenvolvido nos Estados Unidos um "mito Hegel", que era aplicado a Croce de forma maliciosa e ignorante. Era um mito que pairava sobre as mentes de muitos pensadores americanos da primeira metade do século vinte, especialmente aqueles que se encontravam em conflito aberto com o próprio hegelianismo da juventude. Contudo, da mesma forma como Croce fora rotulado de hegeliano, poderia também ter sido rotulado de kantiano, herbartiano, de sanctiano, vichiano, pois sofrera a influência de todos esses pensadores. De acordo com Simoni, as incompreensões em torno de Croce na América do Norte se deviam ao estereótipo idealista que lhe foi aplicado. $\mathrm{O}$ autor lamenta que as referências a Croce, na literatura daquela época, constituíssem "uma comédia de erros" (SIMONI, 1952, p. 9). A forte relação entre o pragmatismo e o neoidealismo, aproximando o pensamento de Dewey e o de Croce, foi tema da pesquisa de Destler (1950), um historiador contrário ao neoidealismo. Para Destler, a ideia de que a história é sempre história movida por interesses do presente desemboca numa concepção relativista, tendência que, para ele, não é uma produção norte-americana, mas recebeu um conteúdo novo na América. Denomina essa tendência de "presentismo" e afirma que, dentre as fontes da introdução do relativismo nos Estados Unidos, encontra-se o trabalho de Croces.

5 De acordo com Destler (1950), a influência do presentismo cresceu nos Estados Unidos depois da segunda guerra mundial. Adam Schaff (1978) concorda com esse argumento e afirma que, dentre os historiadores norte-americanos que seguiram o presentismo, estão Robinson (1912) e Barnes (1937). 
Mais recentemente, as ideias de Dewey voltaram à tona nos Estados Unidos por influência de Richard Rorty (1982), mas não o seu confronto com Croce. Todavia, segundo Roberts (1995), a retomada de questões em torno do presentismo e do relativismo pelos historiadores nos Estados Unidos, na década de noventa do século passado, sugeriu que o diálogo entre o historicismo de Croce e a tradição de Dewey, aparentemente encerrado quarenta anos antes, deveria necessariamente ser retomado.

Roberts afirma que quando Dewey produziu Art as experience não deu muita atenção ao que Croce escreveu sobre o tema. Contudo, teria sido possível um diálogo entre ambos, tendo em vista os papéis similares que desempenharam em suas respectivas culturas. A despeito das substanciais diferenças entre eles, ambos procuravam explicar o mundo em termos de liberdade humana. Entretanto, quando os dois se confrontaram entre si, já no final da vida, "o debate intelectual não foi significativo".

De acordo com Douglas $(1970)^{6}$, historiador norte-americano, Croce não compreendeu, em suas duas resenhas, o profundo desacordo existente entre seu pensamento e o de Dewey. Todavia, assinala Douglas, a filosofia da experiência de Croce não era assim tão diferente da de Dewey, como está sublinhado em Experience and nature (DEWEY, 1925). Embora as terminologias de Croce e de Dewey diferissem entre si, havia muita similaridade entre o pensamento de ambos, mais do que cada um deles reconhecia, especialmente quando tanto um quanto o outro acentuava a continuidade da arte como experiência comum. Portanto, existiu a possibilidade de um debate entre eles, consideravelmente mais profícuo do que o ocorrido.

Já na Itália, o debate entre Dewey e Croce tem uma bela análise de Corrado Maltese ${ }^{7}$, na introdução que escreveu em 1949 à tradução do livro de Dewey Art as experience.

\footnotetext{
6 Segundo Roberts (1995), o trabalho de Douglas é um dos melhores em inglês, além do autor conhecer bem o conceito de "intuição" de Croce, que causa muitas dificuldades aos comentadores norte-americanos.

7 Maltese foi historiador da arte na Itália, especialista em História da arte medieval e moderna, temas que lecionava na Universidade de Genova. Aderiu ao Partido Comunista Italiano em 1956, sendo um dos primeiros a assinar um manifesto contra a repressão soviética na Hungria.
} 
Maltese faz sua análise no calor do debate entre os dois intelectuais, mostrando-se sensível ao apelo que Croce tinha lançado para um debate com Dewey. E concorda com todas as críticas apresentadas por Croce ao livro de Dewey. As afirmações de Dewey, sustenta Maltese, não são consequentes e coerentes com as teorias empiristas e pragmatistas que professa. Em Reconstruction on philosophy (1920), Dewey afirma que a evolução da ciência e o surgimento, em geral, de novos e potentes fatores históricos tornaram possível a formulação de um novo princípio filosófico, isto é, aquele do ponto de vista pragmático da realidade. Todavia, ele se recusa explicitamente a ligar (ele diz com desprezo 'deduzir') a sua teoria filosófica geral à pesquisa sobre a natureza da experiência estética. Além disso, concebe a arte de tal modo desligada do resto do conhecimento, como se ela fosse uma forma superior de conhecimento. Com uma ponta de ironia, Maltese diz que a forma suprema de arte, pensada por Dewey, é reduzida à "arte de fazer quadros que satisfaçam às exigências filosóficas e de gosto dos grandes colecionadores do tipo do Dr. Barnes", a quem Dewey dedica seu livro Art as experience.

Maltese faz uma observação que, depois, vai aparecer na análise de outros autores sobre a recepção de Dewey na Itália, como Lamberto Borghi (1977), um educador deweyano. Segundo Maltese, há no pensamento de Dewey muitos aspectos que poderiam ser chamados marxistas (MALTESE, 1967, p. XXVII). Um deles refere-se à concepção de filosofia de Dewey, compreendida como "um reflexo dos mais amplos e profundos fatos culturais, necessidades, conflitos e problemas" (SCHILPP, p. 522 apud Maltese, 1967,p. XXVII). Em Dewey, se um problema é urgente em filosofia o é porque "é urgente na vida cultural atual". Para Dewey, a atividade especulativa não tem superioridade em relação a outras atividades e, em sua origem, "era intrinsecamente uma teoria de classes ociosas". Ela tem influência "ao justificar o estado da sociedade, no qual apenas poucos são privilegiados, e assim perpetuar as suas condições (...)" (MALTESE, 1967, p. XXVII). Outro aspecto da proximidade entre Dewey e o marxismo é o

\footnotetext{
8 Albert C. Barnes foi aluno de Dewey e defendia seu pragmatismo. Era também um industrial e tinha uma coleção de arte bastante conhecida por Dewey, tendo sido a fonte de muitas ilustrações de seu livro Art as experience. Além de serem amigos, Dewey era membro da Fundação Barnes.
} 
de que o educador norte-americano identifica o aparecimento na sociedade moderna, industrializada, de uma separação entre arte e vida e propõe uma "profunda alteração" das relações sociais como única maneira de permitir à arte reconquistar sua plena função (MALTESE, 1967, p. XXVIII).

No entanto, observa Maltese, as citações de Dewey parecem também ignorar completamente o pensamento marxista em geral e ainda mais aquele sobre a arte. Além disso, não explicita quais são as classes que considera "ociosas", um termo que é mal definido, e nem quais são as "alterações" das relações sociais que ele considera necessárias. A impressão de Maltese é a de que Dewey, tão logo enuncia uma ordem de conflitos, procura atenuá-la, disfarçando aquilo que afirmou. Consequentemente, a concepção de Dewey está 'longe de ser uma 'aproximação' ou mesmo uma 'superação' do marxismo” (MALTESE, 1967, p. XXX).

Maltese considera que a pesquisa de Dewey sobre a arte não passou de uma "conciliação" das "originárias aspirações realistas, científicas, 'tecnológicas' do pragmatismo da própria burguesia americana na fase ascendente, com o individualismo, o subjetivismo absoluto, o idealismo filosófico mais ou menos definidos e cristalizados da burguesia americana que chegou ao seu estágio de maturação" (MALTESE, 1967, p. XXXXXXI). Mas isso não destruiria "o fascínio de certas intuições de Dewey, a felicidade e o interesse de tantos de seus apontamentos e motivos e, em suma, a riqueza de sua humanidade" (MALTESE, 1967, p. XXXI).

Outra é a avaliação do debate entre Croce e Dewey feita por Borghi (1977), o qual reconhece a influência idealista sobre o conceito de arte de Dewey, mas discorda da tese de Maltese sobre o conservadorismo da posição de Dewey. Para Borghi, entre os anos de 1931 e 1934, quando Dewey se empenha em dar forma definitiva à sua concepção de arte "mais rigorosa é a sua crítica à sociedade existente, não somente com relação ao nazismo, mas também ao capitalismo monopolista dos países industriais avançados, inclusive os Estados Unidos" (BORGHI, 1977, p. VIII). Enfim, Borghi sustenta que na estética de Dewey se encontram expressões relevantes que convidam à tentativa de um confronto com a estética marxista.

Neste século XXI, o debate entre Dewey e Croce foi retomado na Itália, dando lugar ao congresso Croce e Dewey cinqüenta anos depois, cujas palestras foram publicadas num livro de título homônimo, 
organizado por Colonnello e Spadafora (2002). Ambos os autores assinalam que o retorno do debate sobre Croce na Itália ocorreu depois de um longo período de desatenção e de esquecimento, embora nesse período as publicações croceanas, incluindo suas cartas, tenham tido um relativo sucesso. A retomada da sua correspondência com Dewey poderia contribuir para compreender o possível papel que as duas filosofias teriam na cultura contemporânea. Para os autores, embora Croce tenha enfatizado a questão da contradição entre as premissas teóricas de Dewey e a sua teoria sobre a estética, ele reconhece que existe no livro Art as experience uma formulação original.

Renata Cavalieri (2002), também participante do congresso sobre Croce e Dewey, procura identificar a existência de um terreno teórico comum entre eles, no plano da filosofia. A autora considera que ambos se interrogavam sobre as finalidades do conhecimento e ambos estavam "convencidos que a relação homem-mundo deve requerer uma capacidade de pensar bem diferente da pura contemplação (...)". Croce e Dewey, prossegue Cavalieri, compartilhavam também de uma comum aversão por qualquer posição extremista e tinham "um comportamento realmente crítico e ao mesmo tempo jamais hostil, certamente conscientes do fato de que é necessário distinguir entre as manifestações do espírito crítico e o fortalecimento do princípio de autoridade (...)" (CAVALIERI, 2002, p. 185-188).

Se é possível encontrar tantos aspectos comuns entre as posições de Croce e as de Dewey, como o faz Cavalieri (2002), por que o educador estadunidense refutou a possibilidade de um diálogo, sustentando a ausência de um common ground entre eles?

Segundo Michele Maggi (2002), o debate entre Croce e Dewey foi um "confronto falido". Por que?

É Croce, afirma Maggi, quem toma a iniciativa de procurar um diálogo com Dewey. A iniciativa não é apenas aquela do primeiro texto de Croce (1940), no qual ele elabora uma análise do livro Art as experience. Maggi identifica diversos outros textos de Croce nos quais se encontra um movimento filosófico em direção a Dewey. Já em 1931, Croce indicava a presença de um mesmo interesse teórico, entre ele próprio e Dewey, na 
superação do dualismo entre sujeito e objeto9. No após guerra, em 1946, Croce fala de uma "singular coincidência em conceitos e conclusões de uma parte da minha obra com aquela de um filósofo americano, do maior filósofo americano, John Dewey” (CROCE, 1966 apud Maggi, 2002, p. 108). Além disso, Croce tenta avaliar positivamente o pragmatismo, dizendo que as suas

proposições são verdadeiras ou podem ser interpretadas de modo verdadeiro, mas que não estão ligadas à unidade do espírito e por isso não são coerentes e sólidas. E essa sistematização e demonstração que os pragmatistas se refutam a dar, sendo grande o seu aborrecimento com relação à filosofia 'orgânica', tal como a chamam, ou seja, historicamente, a tradição de Kant e de Hegel, que foi chamada idealista (...) (CROCE, 1949 apud Maggi, 2002, p. 108).

O momento máximo do movimento em direção a um diálogo com Dewey se realiza com a resenha de Croce sobre a estética deweyana. É quando, novamente, Croce identifica pontos de concordância entre o seu pensamento e aquele do pragmatista norte-americano.

Da parte de Dewey, observa Maggi, não existe interesse num debate teórico com Croce. Há, ao contrário, uma "declarada indisponibilidade" de Dewey para um diálogo (MAGGI, 2002, p. 112). Todos os pontos de coincidência entre as suas teorias e aquelas de Croce, que este último tinha posto em evidência, são por ele negadas.

O "confronto falido" acaba pouco antes da morte de ambos, Croce com 86 anos e Dewey com 92. E Maggi se pergunta: "Mas era possível um encontro? E sobre quais elementos em comum ele poderia ter sido instituído?" (MAGGI, 2002, p. 113).

A hipótese de Maggi é a de que o diálogo proposto por Croce era "bem mais do que um confronto entre duas escolas" de pensamento (MAGGI, 2002, p. 114). Era um encontro entre duas potências: de uma parte, a expoente América vista como a modernidade; de outra, a Itália de Croce, "da grande cultura, uma Itália ideal que é a própria Europa" (MAGGI, 2002, p. 116). E Maggi decifra a intenção de Croce: "Era dessa

9 Essa ideia, segundo Maggi, aparece no texto de Croce Le due scienze mondane. L'estetica e l'economica, publicado em CROCE, B. Ultimi saggi, III, Bari: Laterza, 1963, p. 56. 
altura que Croce devia olhar um encontro" (MAGGI, 2002, p. 116). Apesar de existirem muitas diferenças teóricas entre os dois pensadores, tratava-se de um "confronto entre duas potências" (MAGGI, 2002, p. 115).

Os diversos autores que examinam a polêmica entre Dewey e Croce tratam de identificar pontos de coincidência e de diferença entre as suas respectivas filosofias. $\mathrm{O}$ conhecimento dos aspectos concordantes e discordantes das filosofias de Croce e Dewey, a proximidade e a distância entre o neoidealismo e o pragmatismo constitui certamente uma pesquisa importante a ser realizada, tendo como referencial as indicações de Gramsci sobre como essas correntes de pensamento assimilaram a filosofia da práxis. E existe um ponto de partida na polêmica entre os dois intelectuais que é muito estimulante: não obstante Croce apresente críticas à concepção de mundo do educador norte-americano, ele reconhece a existência de similitudes entre algumas das suas próprias formulações e aquelas enunciadas por Dewey, seja na teoria da arte, seja na teoria da história. Existiria algo mais que se possa entrever nessa posição de Croce?

A análise de Maggi evidencia uma questão muito interessante: atrás do desejo de Croce de ser reconhecido por Dewey como um interlocutor, encontra-se a possibilidade de alçar sua personalidade do plano europeu ao plano internacional, como intelectual cosmopolita. Um "papa laico", diria Gramsci, mesmo que Maggi não mencione esse conceito. E, não por acaso, Maltese também considera Dewey um "papa laico". Segundo Maltese, Dewey sempre "intervinha para tomar posições nos grandes problemas da classe dirigente americana com sua voz um pouco tímida (shy), com o seu discurso um pouco obscuro e difícil, desenvolvendo quase uma função de 'Papa laico' (para usar a expressão de Gramsci) similar àquela desenvolvida por Benedetto Croce na Itália” (MALTESE, 1967, p. VIII).

Encontramo-nos, pois, diante de uma disputa entre dois "papas laicos"?

\section{Croce e Dewey: "Papas laicos"? A interpretação de Gramsci}

Por que Gramsci usa a expressão "papa laico" para explicar a posição de Croce?

O conceito de "papa laico" aplicado por Gramsci ao papel de Croce 
como intelectual se refere à sua reflexão sobre quem poderia representar melhor a cultura italiana no exterior: o papa, Croce ou Gentile? Qual tipo de representação?

Trata-se da representação hegemônica, isto é,

1) quem tem mais importância do ponto de vista da hegemonia, como ordenador da ideologia que dá o cimento mais íntimo à sociedade civil e, assim, ao Estado; 2) quem representa melhor no exterior a influência italiana no quadro da cultura mundial (GRAMSCI, 1977, p. 1306).

Gramsci considera difícil responder à questão da representação da cultura italiana no exterior porque entende que Croce, Gentile e o papa dominam ambientes e forças diversas. A sua conclusão, entretanto, é a de que Croce é o "papa laico", não obstante sua moral não possa se tornar popular porque é intelectual demais e "do tipo Renascimento, enquanto o papa e sua doutrina influenciam enormes massas do povo com máximas de conduta que se referem até às coisas mais elementares" (GRAMSCI, 1977, p. 1307).

Croce quer assumir a posição de "leader mundial da cultura", uma espécie de função "intelectual cosmopolita". Tal preocupação aparece quando assume "posições sempre equilibradas, olímpicas, sem compromissos muito arriscados de caráter provisório e episódico" (GRAMSCI, 1977, p. 1303). Croce se interessa em "elevar o tom da vida intelectual na Itália através do contato e do intercâmbio de idéias com o mundo internacional" como estratégia para desprovincializar a cultura e o costume (que ainda perduravam na Itália). (GRAMSCI, 1977, p. 1303). Existe, na sua posição e na sua função, acrescenta Gramsci, um princípio essencialmente nacional.

Gramsci conhece as publicações de Croce sobre a estética no exterior (Breviario d'estetica. Aestethica in nuce, 1992) e sublinha que a análise das suas posições deveria considerar alguns aspectos da sua atividade, tais como:

1) Croce como teórico da estética e da crítica literária e artística;

2) Croce como crítico da filosofia da práxis e como teórico da 
historiografia; 3) especialmente Croce como moralista e mestre de vida, construtor de princípios de conduta que são alheios a qualquer confissão religiosa, ou melhor, mostram como se pode 'viver sem religião'. (GRAMSCI, 1977, p. 1303).

Assumir a função de "papa laico" significa, em suma, desenvolver uma posição que torne possível a representação hegemônica de uma cultura no exterior, trabalhar "como ordenador da ideologia que dá o cimento mais íntimo à sociedade civil e assim ao Estado"; viver sem religião.

No que concerne à função de Croce como "papa laico" ou "líder mundial", Gramsci se refere à sua participação no Congresso de Filosofia de Oxford (1930) porque considera que o estudo da posição prática de Croce é um elemento importante para analisar sua posição filosófica. O discurso de Croce (CROCE, 1930) na seção de Estética do mencionado Congresso, observa Gramsci, é "um manifesto político, de uma união internacional de grandes intelectuais de cada nação, especialmente da Europa; e não se pode negar que isso possa se tornar um partido importante que pode ter uma função que não é pequena (...)" (GRAMSCI, 1977, p. 690). Naquele Congresso, Croce desenvolveu uma crítica extrema à filosofia da práxis e o seu discurso não pode ser visto como uma afirmação de filósofo, mas como um ato político de "efeito prático imediato" (GRAMSCI, 1977, p. 1291), porque ele não apenas renega a sua posição assumida antes de 1900, mas renega também a "sua filosofia passada" (GRAMSCI, 1977, p. 1298). E sobre esse aspecto Gramsci se pergunta:

Pode-se dizer, todavia, que na concepção de Croce, mesmo depois da elaboração feita nesses últimos anos, não existam mais traços da filosofia da práxis? O historicismo de Croce não tem mesmo mais nenhuma influência da sua experiência intelectual dos anos que vão de 1890 a 1900? (GRAMSCI, 1977, p. 1232).

Gramsci afirma que também na forma e na linguagem especulativa é possível encontrar na concepção de Croce mais de um elemento que mostra a influência da filosofia da práxis. Em seu entender, uma pesquisa sobre esse tema teria um imenso significado histórico e intelectual. E diz 
ainda: "assim como a filosofia da práxis foi a tradução do hegelianismo em linguagem historicista, a filosofia de Croce é igualmente, em grande medida, uma retradução em linguagem especulativa do historicismo realista da filosofia da práxis" (GRAMSCI, 1977, p. 1233). Por isso, Gramsci propõe "acertar as contas com a filosofia de Croce", do mesmo modo como Marx acertou as contas com a filosofia clássica alemã (GRAMSCI, 1977, p. 1234).

A historiografia de Croce, segundo Gramsci, é um hegelianismo mutilado e degenerado porque demonstra temor de qualquer intervenção ativa das massas populares como fator de progresso histórico. Ele observa que existe em Proudhon a mesma mutilação do hegelianismo e, por isso, a concepção contida na Miséria da filosofia (MARX, 1976) se aplica como crítica historiográfica também à concepção da história de Croce (GRAMSCI, 1977, p. 1220). A mutilação aparece no fato de que, no processo dialético, “a tese deve ser 'conservada' pela antítese para não destruir o próprio processo, que, portanto, é 'previsto', como uma repetição ao infinito" (GRAMSCI, 1977, p. 1221).

Tal mutilação não se encontra em Hegel (GRAMSCI, 1977, p. 1220-1221). Na dialética real, não se pode prever o que será o resultado da antítese. Gramsci sustenta que o erro da ideia de previsão ali presente é o de "elevar a momento metodológico o que é pura imediatidade, elevando portanto a ideologia ao nível de filosofia" (GRAMSCI, 1977, p. 1221). A tentativa para controlar a síntese dialética se configura como um "transformismo".

Segundo Gramsci, a mutilação da dialética se insere no âmbito de uma revisão da filosofia da práxis feita por intelectuais "puros" (Croce, Gentile, Sorel, Bergson e também pelo pragmatismo). A revisão consiste na seguinte metodologia: alguns elementos da filosofia da práxis são absorvidos e incorporados por algumas tendências idealistas. "Os intelectuais "puros', como líderes dos grupos intelectuais de seus países" (GRAMSCI, 1977, p. 1855) encontraram na filosofia da práxis um novo elixir para fortalecer politicamente o grupo social ao qual se vinculavam e, assim, poder afrontar a profunda crise de hegemonia da classe dominante frente à ascensão do movimento operário. Na filosofia da práxis - com o seu realismo historicista - os intelectuais "puros" encontraram uma nova fonte teórica para alimentar a filosofia especulativa. 
O procedimento de mutilação da dialética descrito por Gramsci é caracterizado como "revolução passiva" ou "transformismo". Ele consiste, portanto, na importação de alguns elementos da filosofia da práxis para dar nova vitalidade às filosofias tradicionais. E Gramsci identifica ao menos dois aspectos que demonstram a presença da filosofia da práxis no pensamento de Croce: a identidade de história e filosofia e a doutrina sobre as ideologias políticas.

Em relação à identidade entre história e filosofia, Gramsci afirma que ela é imanente à filosofia da práxis, mas tornou-se outra coisa bem diferente na concepção de Croce. Todavia, Gramsci considera a concepção de Croce, no que tange à identidade entre história e filosofia, "rica de conseqüências críticas" (GRAMSCI, 1977, p. 1241). Uma das consequências mais importantes é a de que a identidade de história e filosofia conduz à identidade de história e de política e, portanto, "também à identidade de política e de filosofia" (GRAMSCI, 1977, p. 1241). Se o político é um historiador, o historiador é um político. Por isso, seria possível dizer que a história é sempre contemporânea: porque é política (GRAMSCI, 1977, p. 1242). No entanto, essa conclusão não está presente na concepção de Croce porque a identificação de história e política traz também a identificação de ideologia e filosofia.

Com respeito à doutrina de Croce sobre as ideologias políticas, Gramsci afirma que ela

deriva claramente da filosofia da práxis: são construções práticas, instrumentos de direção política, isto é, poder-se-ia dizer, as ideologias são para os governados meras ilusões, um engano imediato, enquanto são para os governantes um engano desejado e consciente" (GRAMSCI, 1977, p. 1319).

Ao contrário disso, continua Gramsci, para a filosofia da práxis as ideologias não são arbitrárias, mas são

fatos históricos reais, que é necessário combater e desvendar a sua natureza de instrumentos de domínio não por razões de moralidade etc., mas sim por razões de luta política: para tornar os governados intelectualmente independentes dos governantes, para destruir uma 
hegemonia e criar uma outra como momento necessário da reversão da práxis (GRAMSCI, 1977, p. 1319).

Por isso, a filosofia da práxis não "tende a resolver pacificamente as contradições existentes na história e na sociedade, mas é a própria teoria de tais contradições" (GRAMSCI, 1977, p. 1320). O historicismo de Croce, ao inverso, é "uma forma de moderação política, que põe como único método de ação política aquele no qual o progresso, o desenvolvimento histórico, resulta da dialética de conservação e inovação", um verdadeiro reformismo (GRAMSCI, 1977, p. 1325).

A concepção de Croce da "dialética" é simplesmente escolástica, vazia, sem vigor e grandeza. No seu historicismo, há uma relação com a tradição moderada do Ressurgimento e o pensamento reacionário da Restauração. Ao mesmo tempo, o seu historicismo "é um dos pontos e dos motivos permanentes em toda a atividade intelectual e filosófica" de Croce e uma das razões de sua influência intelectual durante trinta anos. Com base nessa reflexão, Gramsci considera fundamental identificar exatamente o historicismo de Croce, porque isso significa

reduzi-lo à sua real dimensão de ideologia política imediata, destituindo-o da grandeza brilhante que lhe é atribuída, como se fosse manifestação de uma ciência objetiva, de um pensamento sereno e imparcial que se coloca acima de todas as misérias e contingências da luta cotidiana, de uma contemplação desinteressada do eterno vir-aser da história humana (GRAMSCI, 1977, p. 1327).

$\mathrm{Na}$ função de "papa laico", desenvolvida por Croce, estaria compreendida a atividade transformista. Seu historicismo, diz Gramsci, não é ciência, mas ideologia.

A esse propósito, os diversos pontos de vista, aqui focalizados sobre a polêmica entre Croce e Dewey, não levam em consideração a perspectiva identificada por Gramsci: a assimilação da filosofia da práxis, tanto pelo neoidealismo quanto pelo pragmatismo.

No que diz respeito a Dewey, seria também ele um "papa laico" como o chama Maltese? Teria Croce reconhecido que o common ground de suas respectivas filosofias se encontrava numa espécie de aliança de 
intelectuais cosmopolitas que teriam como objetivo tomar uma posição política conservadora em nível internacional?

\section{Considerações finais}

Os princípios morais propostos por Dewey no início do século XX tinham o objetivo de construir a hegemonia da burguesia industrial e do modo de vida "americano". A escola progressiva, sua proposta político-pedagógica, se apresentava como um instrumento para obter o consentimento dos grupos sociais subalternos. Tratava-se de educar os indivíduos para que assumissem como suas as novas exigências da sociedade industrial. O contexto no qual Dewey trabalha é marcado pelo revigoramento do capitalismo nos Estados Unidos e pela consolidação da hegemonia industrial norte-americana, processo conhecido como “americanismo". Refere-se a uma renovação sem precedentes do movimento de industrialização, que assumiu um caráter especial por ser estimulado por forças empresariais "jovens", que não se sentiam bloqueadas, como ocorria na Europa, por formas parasitárias da apropriação privada da riqueza socialmente produzida.

A pedagogia de Dewey, portanto, tinha vínculos com a cultura e os valores morais e sociais da sua época (CREMIM, 1964). Ele não concordava com a ideia segundo a qual os valores culturais e morais eram estabelecidos através da imposição (força) porque aspirava conquistar a "auto-disciplina voluntária". A tentativa de obter o consentimento voluntário por meio da persuasão se baseava na perspectiva de difusão de valores culturais e morais que condensassem as diretivas do novo projeto político do grupo social dominante.

Na sua filosofia da educação, Dewey deu ênfase à reconstrução do passado, como aparece nas suas obras The school and society (originalmente publicada 1899) e Democracy and education (primeira edição de 1916). De acordo com Karier e Hogan (1982), o argumento central do educador norte-americano é o de que a história industrial do homem pode ser tratada como sua luta contra a natureza, por meio do uso racional da ciência e da tecnologia para vencer a natureza. Contudo, Dewey não fala do conflito 
entre os homens e muito menos do controle social do sistema capitalista e dos objetivos de tal controle. E a não consideração desse aspecto pode ser vista como intencional.

O conceito de história como história contemporânea, afirmam Karier e Hogan, é empregado por Dewey para dar suporte às implicações sociais contidas no tempo presente. O seu ponto de partida é o "presente problemático", como afirma em Democracy and education. Para Dewey, acrescentam os autores citados, a história era um instrumento usado para modelar a consciência no sentido de solucionar problemas presentes. Muitas vezes Dewey apresentou a definição do presente e dos seus problemas em termos de um atraso cultural, cuja origem era o progresso da ciência e da tecnologia em alguns setores da vida e a incapacidade de outros setores da vida de seguir na mesma velocidade. De acordo com os mencionados autores, Dewey acreditava que a solução desse problema não seria encontrada na extensão da ciência e da tecnologia a todas as áreas de vida, mas no aumento da fé na ciência e na tecnologia. Esse objetivo deveria ser facilitado pela construção da história. Nesse quadro, Dewey considerava que "O conhecimento do passado só tem significado se contribuir para o aprofundamento e a ampliação da nossa compreensão do presente". (DEWEY apud: KARIER; HOGAN, 1982, p. 123). Entretanto, alguns problemas, como os conflitos entre os homens, a luta de classes, enfim, o preço de sangue pago pela humanidade para garantir o progresso científico e tecnológico não são focalizados na perspectiva de Dewey sobre a educação. Os autores concluem que mesmo se

a realidade social criada por Dewey pareça externamente benigna, racional, e às vezes até socialista, inserida no contexto histórico dos acontecimentos educacionais do século vinte, a filosofia liberal progressiva que ele propôs teve a conseqüência pragmática de preservar o controle hegemônico daqueles que governam a sociedade americana (KARIER; HOGAN, 1982, p. 127).

Consequentemente, teria razão Maltese quando se refere a Dewey como o "papa laico"? 
No momento, é possível dizer que tanto a filosofia de Dewey quanto a de Croce contribuíram para a realização do fenômeno do "transformismo". No caso do educador norte-americano, ao mesmo tempo em que suas ideias pedagógicas eram apresentadas como elemento para o progresso científico, tecnológico e a ampliação da democracia, elas também eram um instrumento para consolidar a hegemonia das forças sociais burguesas nos Estados Unidos no início do século XX.

Contudo, se existem tantos argumentos que mostram a proximidade entre a filosofia de Dewey e aquela de Croce, por que Dewey insistiu na tese da falta de um common ground entre seus respectivos pensamentos?

\section{Referências}

BARNES, H. E. A History of historical writing. Norman, Oklahoma: University of Oklahoma Press, 1937.

BORGHI, L. Prefazione a Dewey, J. Educazione e arte, editado por L. BELLATALLA, Firenze: La Nuova Italia, 1977.

CAVALIERE, R. V. La teoria della conoscenza in Croce e Dewey. In: COLONNELlO, P.; SPADAFORA G. (Org.). Croce e Dewey, cinquanta anni dopo. Napoli: Bibliopolis, 2002, p. 179-200.

COLONNELLO, P.; SPADAFORA, G. (Org.). Croce e Dewey, cinquanta anni dopo. Napoli: Bibliopolis, 2002, p. 9-20.

CREMIN, L. A. The transformation of the school: progressivism in American education 1876-1957. New York: Vintage Books, 1964.

CROCE, B. Antistoricismo. La Critica, 20 novembre, 1930 (anno XXVIII, fasc. VI), p. 401-09. Depois, o livro foi publicado novamente em Croce, B. Punti di orientamento della filosofia moderna. Antistoricismo. Due Lettere ai Congressi Internazionali di filosofia di Cambridge (Mass) 1926 e di Oxford 1930, Bari: Laterza, 1931.

. Breviario di estetica. Aesthetica in nuce, Milano: Adelphi, 1992.

. Dewey's aesthetics and theory of knowledge. The Journal of

Aesthetics and Art Criticism, v. 11, n. 1, p. 1-6, Sep 1952.

. Estetica come scienza dell'espressione e linguistica generale, 
Milano: Adelphi, 2005 (primeira edição de 1902).

. Intorno all'estetica de Dewey. La Critica, XXVII, 1940, p. 348353, publicado também em CROCE, B. Discorsi de varia Filosofia, v. 2, Bari: Laterza, 1945, p. 112-119.

. Intorno all'estetica e alla teoria del conoscere del Dewey. $L a$ Critica, v 6, n. 16, 1950, p. 61-68. Também publicada em CROCE, B. Indagini su Hegel e schiarimenti filosofici, edição crítica organizada por A. Savorelli, Napoli: Bibliopolis, 1998, p. 295-304.

. Storia, cronache e false storie, originalmente publicada em Atti dell"Accademia pontaniana, de 1912, e depois em Croce, B. Teoria e storia della storiografia, cuja primeira edição é 1916. O texto foi traduzido para o inglês e publicado como CROCE, B. The theory and history of historiography (traduzido por Douglas Ainslie), London: Harrap, 1921.

. Teoria e storia della storiografia. 1. ed. Bari: Laterza, 1916.

. The theory and history of historiography, Traduzido por Douglas Ainslie, London: Harrap, 1921.

DE RUGGIERO, G. Filosofi del novecento. Bari: Laterza, 1946, p. 63-87. Também publicado In: La Critica, v. XXIX, 20, fascículo de setembro de 1931, p. 341-357.

DESTLER, C. M. Some Observations on Contemporary Historical Theory. The American Historical Review, v. 55, n. 3, p. 503-529, Apr. 1950.

DEWEY, J. Art as experience. New York: Minto; Balch, 1934.

. Democracy and education: An introduction to the philosophy of education. New York: The Macmillan Company, 1930. . Experience and nature. Chicago \& London: Open Court, 1925. . L'arte come esperienza. Firenze: La Nuova Italia, 1951. Company, 1920.

. Reconstruction in philosophy. New York: Henry Holt and . Ricostruzione filosofica. Bari: Laterza, 1931.

. The school and society: Being Three Lectures, Supplemented by a Statement of the University Elementary School, Chicago: University of Chicago Press, 1899. 
. A Comment on the Foregoing Criticisms. The Journal of Aesthetics and Art Criticism, v. 6, n. 3, p. 207-209, Mar. 1948.

DOUGLAS, G. H. A Reconsideration of the Dewey-Croce exchange. The Journal of Aesthetics and Art Criticism, v. 28, n. 4, p. 497-504, Summer 1970.

GRAMSCI, A. Quaderni del carcere. 4 vols. Turim, Einaudi, 1997.

KARIER, C. J.; HOGAN, D. Schooling, education and the structure of social reality. In: TILES, J. E. (editor). John Dewey: critical assessments. London and New York : Routledge. 1982, p. 109-130.

KLOPPENBERG J. T. Pragmatism and the practice of History: from Turner and Du Bois to today. Metaphilosophy, Oxford, v. 35, n. 1-2, p. 202-225, Jan. 2004.

MAGGI, M. Aristocrazia civile e cosmopoli democratica: le filosofie pubbliche di Croce e Dewey. In: COLONNELlO, P.; SPADAFORA, G. (Org.). Croce e Dewey, cinquanta anni dopo. Napoli: Bibliopolis, 2002, p. 107-136.

MALTESE, C. L'Estetica di J. Dewey (Presentazione, 1949) In: DEWEY, J. L'arte come esperienza. Firenze: La Nuova Italia, 1967 (1ª edição em 1951).

MANCINA, C. Praxis e pragmatismo: tracce di James nel pensiero di Gramsci. In: VACCA, G. (Org.). Gramsci e il Novecento. v 1, Roma: Carocci, 1999, p. 311-330.

MARX, K. Miséria da filosofia. São Paulo: Grijalbo, 1976.

META, C. Filosofia della prassi e pragmatismo. Critica Marxista. Roma, n. 2/3, p. 41-53. 2004

PEPPER, S. C. Some questions on Dewey's esthetics. In: SCHILPP, P. A. (Org.). The Philosophy of John Dewey. Evanston: Northwestern University Press, 1939, p. 369-390.

ROBERTS, D. Croce in America: influence, misunderstanding, and neglec, humanitas. Washington, v. 8, n. 2, National Humanities Institute, 1995. Disponível em: $<$ http://www.nhinet.org/roberts.htm>. Acesso em: 27 Maio 2005.

ROBINSON, J. H. The new history: essays illustrating the modern historical 
outlook. New York: Free Press, 1912.

ROMANELL, P. A. Comment on Croce's and Dewey's aesthetics. The Journal of Aesthetics and Art Criticism, v. 8, n. 2, p. 125-128, Dec. 1949.

RORTY, R. Consequences of pragmatism (Essays: 1972-1980). Minneapolis: University of Minnesota Press, 1982.

SCHAFF, A. História e verdade. Rio de Janeiro: Martins Fontes, 1978.

SIMONI, F. S. Benedetto Croce: A case of international misunderstanding. The Journal of Aesthetics and Art Criticism, v. 11, n. 1, p. 7-14,Sept. 1952. URBINATI, N. L'individuo democratico tra Tocheville, Gramsci e Dewey. In: VACCA, G. (Org.). Gramsci e il novecento. v. 1Roma: Carocci, 1999, p. 295-310.

Data de registro:03/10/2011 Data de aceite:03/10/2012 